\title{
Free fare policy as a tool for sustainable development of public transport services
}

\author{
Daniel Štraub*, Václav Jaroš \\ Charles University in Prague, Czechia
}

This article focuses on free fare public transport policy (FFPT) as an example of the sustainable mobility paradigm FFPT is one of a number of instruments through which a balance between the economic costs and efficiency in the public transport system can be reached. Even though the strategic approach of FFPT systems is used worldwide, their implementation is somewhat sporadic. By investigating examples of currently or formerly existing free fare public transport schemes, this study analyses the overall ability of FFPT to reach the strategic targets required. The study identifies four key areas that the municipalities are trying to target (reducing car use externalities, social justice/benefits provision, increasing the efficiency of public transport, and promoting sustainable means of transportation). As the specific conditions of each locality generate particular issues, the strategy of each transport system authority differs from one to another. It is, therefore, necessary for the transport planning authorities to implement various tools (both supportive and repressive) whose synergies will target the main objectives. A systematic and conceptual approach is what underpins the successful development of the urban transport system in the long-term.

Key Words: Free fare transport, public transport policy, transport geography, sustainable transport, transport justice, Frýdek-Místek.

Article Info: Received: April 5, 2019; Revised: May 9, 2019; Accepted: May 18, 2019; Online: May 31, 2019.

\footnotetext{
${ }^{*}$ Corresponding author

Address: Charles University in Prague, Faculty of Science, Department of Social Geography and Regional Development, Albertov 6, Prague, Czechia.

Phone: + 420724867841 | Email: straubd@tuta.io

(C)2019 Human Geographies; The authors

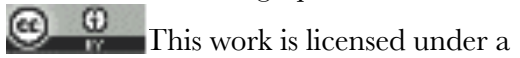

Creative Commons Attribution 4.0 International License. DOI:10.57 19/hgeo.2019.131.3
} 


\section{Introduction}

Issues concerning the operating of transportation systems and their attempt to find a balance between economic costs and general productivity play a significant role in the field of transport research. Primarily due to growing mobility in our society together with new academic currents emerging from the new mobility turn (Sheller \& Urry, 2006); many scholars are examining the paradigm of sustainable mobility (Banister, 2008). This paradigm emphasises that current lifestyles are characterized by a high dependence on various modes of transport, primarily cars, and underscores the fact that this state of affairs is hardly sustainable. This car-dependency is caused by low fixed and variable costs related to individual car transportation as well as the easy access to cars, which is valid around the world. Nowadays, owning a car and using it actively is a natural part of our lives and this behaviour shapes society. As Kenyon et al. (2002) argue 'modern landscapes seem to be designed for healthy forty-year-old men steering cars'. Individuals in such a society are forced by external conditions to use the car as their primary means of transport.

Many researchers (Banister, 2008; Banister \& Marshall, 2000; Banister \& Hickman, 2006; Pojaniy \& Stead, 2015; Green \& Wegner, 1997) highlight the negative impacts of automobiles on quality of life and the environment, for example green gas emissions, noise pollution, traffic congestion, and landscape fragmentation. In addition, the growing use of cars also hurts other means of transport, particularly in the cases of non-motorised or public transport, because the latter ones are less effective. The massive increase in the use of cars and in a car-dependent society is one of the main issues leading to the discrimination of individuals or groups who, for whatever reason, are limited in their access to and use of a car (Church et al., 2000; Kenyon et al., 2002; Preston \& Rajé, 2007; Hine, 2008; Kenyon, 2011; Lucas, 2012). These groups and/or individuals are affected by transport exclusion, which limits their participation in ordinary activities and everyday life as their mobility is lower (Jaroš, 2017). For these reasons, the established trends in transportation are unsustainable in the long term, and therefore, new approaches for contributing to environmental and sustainable development should be created. Even though transport exclusion is mostly perceived as a rural problem, it is now common to find aspects of it even in the urban areas, which are highly exposed to other negative impacts of transport via the high intensity of the use of cars. In general, one could expect that the next few decades will be characterised by increasing tendencies to support urban and transport planning policy strategies which will lead to a reduction in the number of trips made by car users, supporting the use of public transport and promoting other environmentally-friendly means of transport, especially in the urban environment (Banister, 2000). Nowadays, urban planners have a variety of tools at their disposal for organising the development of their traffic networks. A free fare transport policy is one such tool, which is being introduced in many cities of various sizes and levels of economic development. 
This article focuses on the concept of a free fare transport policy as a very specific measure to influence urban traffic systems, mobility and travel behaviour. Besides acting as an introduction to its key features, this paper analyses the different reasons and goals, which drive municipalities to introduce this system. One part of the paper naturally focuses on an evaluation of the free fare transport scheme to reach its primary goals. In doing so, this article examines different cases from a number of cities of various sizes, economic levels, and socio-geographical and physical-geographical conditions where this system has been implemented.

\section{Urban traffic systems}

There is a wide set of tools available for implementing sustainable urban traffic systems. Such tools and measures can be generally divided into three categories (Green \& Wegner, 1997). The first category deals with the support of technological innovations, which can reduce transportation' negative impacts. These innovations include vehicles using alternative fuel systems (electric cars) or partially upgraded models that reduce the vehicle's ecological footprint. The second category includes measures, which attempt to improve the quality of the current transport system to meet the expected demand. Such measures are a part of the transport and urban strategies related to problems like traffic congestion caused by the emergence of new infrastructure, or improving the quality of public transport (new fleets of vehicles, priority lanes, etc.). This category also includes tools, which aim to promote the public transport service, alternative means of transportation (pedestrian, cycling), or restrict and motivate drivers to change their driving behaviour. The third category is rather general and mainly focuses on measures meant to reduce the need for transport. It mainly includes specific steps by urban planners and policymakers to create urban structures where the need for using a car is limited, for example, or suburban planning that focuses on avoiding urban sprawl.

Naturally, each municipality uses different tools depending on their needs and the quality of the local transport system. These tools can be labelled as either motivational or restrictive, as seen in Figure 1, some cities try to tackle overcrowded traffic infrastructure by rebuilding it, others try to prevent cars from entering the city centre and seek to persuade drivers to use public transport, or they promote other modes of transport like walking or riding a bike.

Not surprisingly, supporting measures, which aim to improve the quality and efficiency of public transport, which is considered the main competitor of the personal car, is a very popular tool found in many contemporary transport strategies. The concept of a free fare transport policy represents one possible approach. It is an effective measure used worldwide to promote the use of public transport. However, this approach also has its critics, mainly due to its effects. Some scholars argue that its ability to motivate drivers to use public transport is very similar to improving the quality of public transport, increasing the price of fuel, or other restrictive measures towards drivers (Baum, 1973; Cevero, 1990; 
Haire \& Machemehl, 1992; Litman, 2004; Chen et al., 2011; Cats et al., 2017). It is not possible to perceive specific measures individually within the framework of the whole system. In order to effectively influence transport systems to move towards more sustainability and social justice, it is necessary to adopt a comprehensive set of measures containing both motivational and restrictive instruments. Therefore, a free fare transport policy is one of a set of measures that need to be implemented together over time.

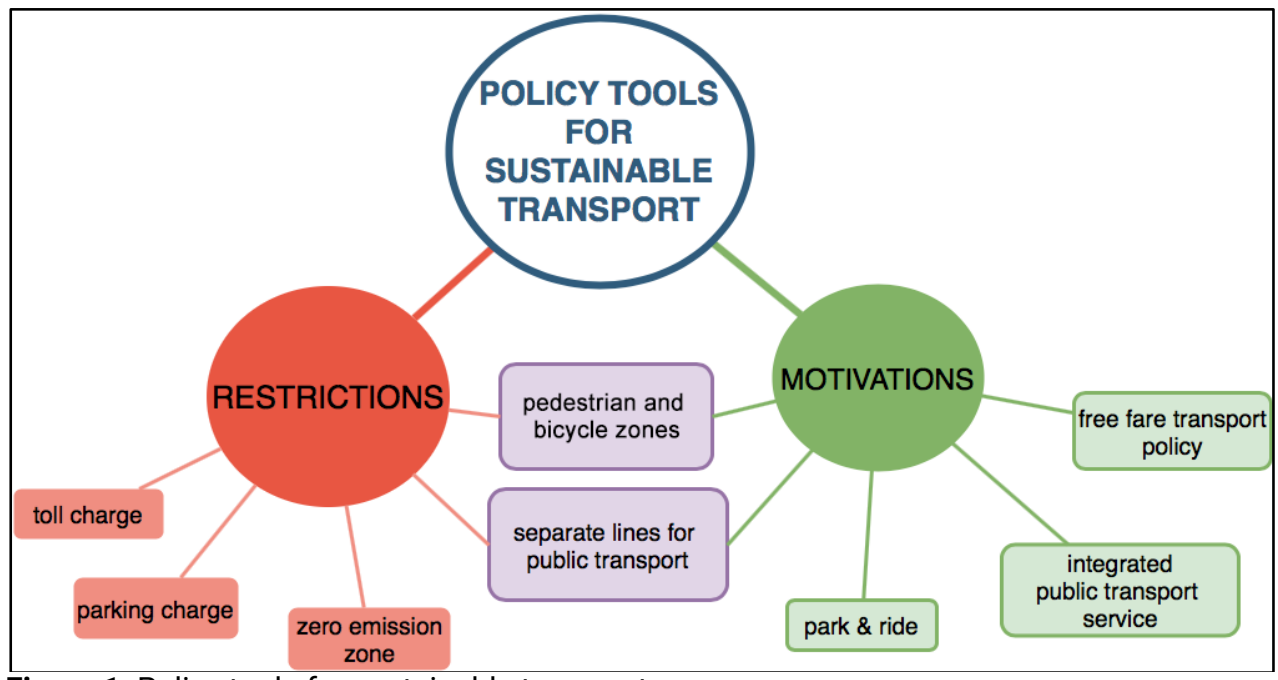

Figure 1. Policy tools for sustainable transport Source: Author's own draft

\section{Free fare public transport}

Free fare public transport schemes (FFPT) emerged during the 1960s and 1970s as a reaction to the growing intensity of car use (Scheiner \& Starling, 1974; van Goeverden et al., 2006; Hess, 2017). At that time, this approach was viewed as a tool to motivate drivers to use public transport to reduce the use of cars and their negative impacts (Baum, 1973). It was a reaction to the massive development of automobiles during the 1960s when city councils realised that current traffic conditions were unsustainable and that it was important to find a solution. Implementation of the project was haphazard and uncoordinated because of the political climate rather than because of any scientific recommendations. This still remains true today. From the time of the first experiments with FFPT, the approach was not only implemented in cities in North America and Europe but also South America, Asia and Australia. The issue is still a sensitive topic throughout society, it remains a neglected subject in social, geographical, and technical research in the field of transport and academic arguments dealing with the concept remain uncommon (Volinski, 2012; Tao, 2013; Cats et al., 2017; Keblowski, 2018). 
The main feature, as one may have already noticed from its name, is that people can use public transport free of charge. Sometimes the policy is used in the service of political populism; however, in many cases and its various forms, the implementation of FFPT is very valuable and plays a crucial role in transport strategy. Free fare transport means that passengers pay no fares, and from the view of the public transport provider, launching it requires substantial changes in the budget and costs of the service. Together with ticket revenue, all costs connected with the tickets themselves (the production and collection of the tickets, accounting, etc.) are also abolished, and this may provide some extra finances to the municipal budget (Perone, 2002; Volinsky, 2012).

However, there are relatively few cases where the introduction of FFPT is financially viable; these are mainly found in small transport systems in which the costs of printing, selling and checking travel documents represents a significant share of the total budget (Hodge, 1994; Cats, 2014). The introduction of FFPT is always a serious intervention in the budget of the public service provider, which, in some cases, attempts to find new financial sources from other parties, the socalled 'third-party payer system', like universities or the private sector (De Witte et al., 2006; Volinsky, 2012). As public transport services' main goal is not to make a profit but to serve individual passengers and society, it is paid for by subsidies from the state with these often being increased after the introduction of FFPT (Bly and Oldfield, 1986; Goeverden et al., 2006; Tetřevová, 2008). The introduction of FFPT represents a transfer of public transport from a mixed public good to a public good.

It is no surprise that every municipality introducing the system of FFPT modifies the scheme according to its own needs and local aspects of the transport system. Not every city using the scheme has abolished fares for everyone across the whole transport network. In reality, unlimited free fare transport policy systems are not often utilised and free transport schemes with specific limitations and settings prevail. The most common forms of the free fare transport concept in use are shown in Table 1.

As shown in Table 1, unlimited free transport is not the only possibility. The most well-known examples of fully implemented free transport schemes include Hasselt (Belgium), Templin (Germany), and Aubagne (France) (Storchman, 2003; Goeverden et al., 2006; Fearnley, 2013). More commonly, regarding unlimited free fare schemes, municipalities introduce the concept for the whole public transport system, but it only applies to residents. This is the case, for example, in Tallinn (Estonia), and Frýdek-Místek (Czechia). Limiting the free public transport scheme to specific groups is also frequently used. The aim is to increase mobility and participation in everyday life as well as road safety on university campuses for specific social groups like students, the elderly, and the disabled (Storchmann, 2003; Jaroš, 2017). Line-limited FFPT seeks to reduce car use in specific parts of the transport system. For example, the bus line between Haag-Leiden (Netherlands), where the bus is only free during weekdays (Goeverde et al., 2006). 
Table 1. Forms of FFPT

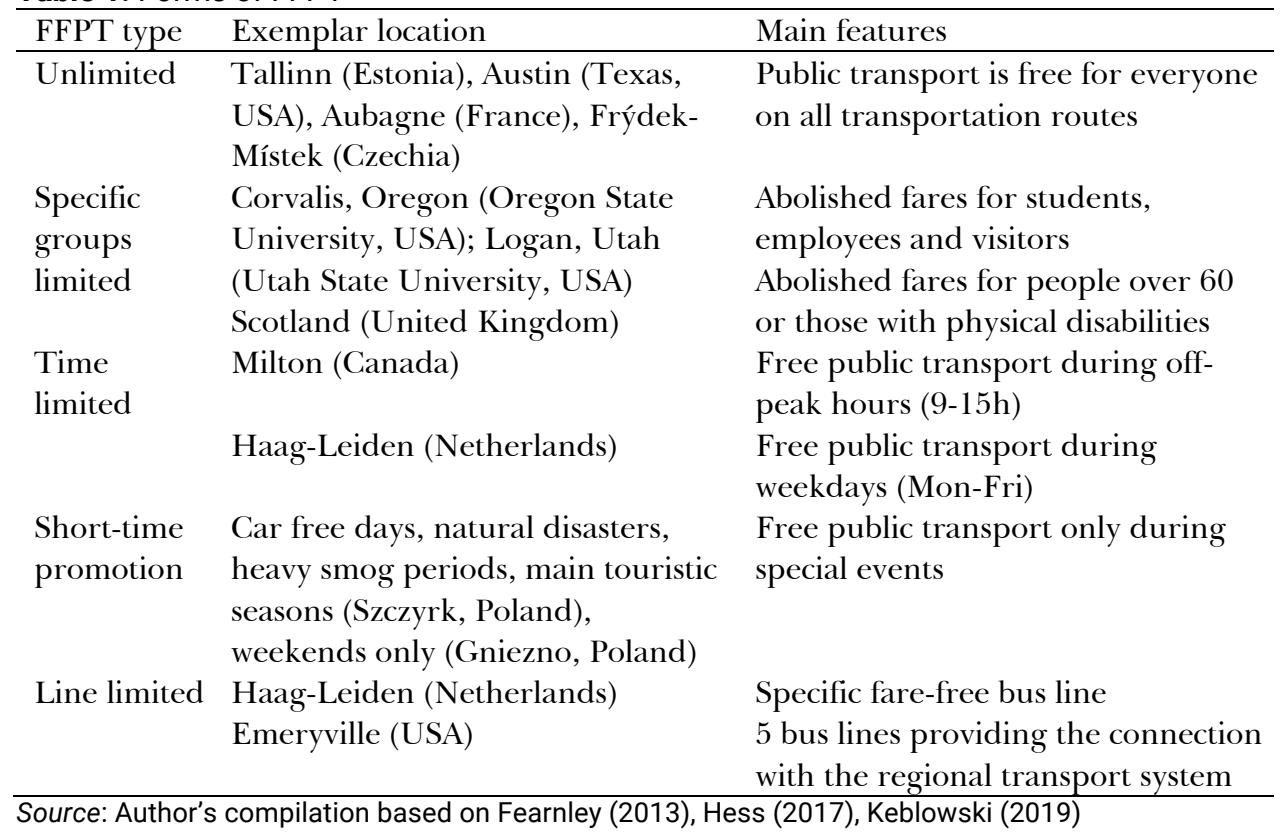

Besides single lines, the system can also be introduced in specifics areas like the city centre, etc. - Stavanger (Norway), Seattle (Washington, USA), Orlando (Florida, USA), Tempe (Arizona, USA) (Volinsky, 2012; Fearnley, 2013). Some public transport providers are using the system to increase its use during off-peak periods. The FFPT scheme is limited only to specific periods, as found, for example, in Milton (Canada), Denver (Colorado, USA), and Trenton (New Jersey, USA) (Hodge et al., 1994; D’Allesandro, 2008). In such cases, there is an increase in ridership in off-peak hours and, at the same time, it improves the quality of service during peak hours by reducing the number of passengers on board the vehicles. Factors such as the quality of public transport play an important role in the decision-making process and may have a big influence on motivating drivers to use public transport, as qualities like comfort and speed are key issues for this target group (Redman et al., 2013). A very particular form of FFPT is the category that provides that public transport is free during special events like New Year's Eve, Car-Free Days, Mobility Week, or in order to promote the service of public transport. Through this step, the municipality is trying to promote special upgrades to public transport (new fleets) and attract new passengers. Other goals could be educating the public about sustainable development or reducing traffic activity during busy days (New Year's Eve, Advent, etc.).

Due to the growing use of FFPT among municipalities, the concept itself is emerging in new forms, which stem from the different needs, characteristics, and goals of particular cities. Naturally, not only the forms of the concept are being modified according to local aspects, but also the main reasons why the free fare transport policy is being implemented. As we can see in Figure 2, there are four main sets of goals, which drive many policymakers to apply FFPT. 


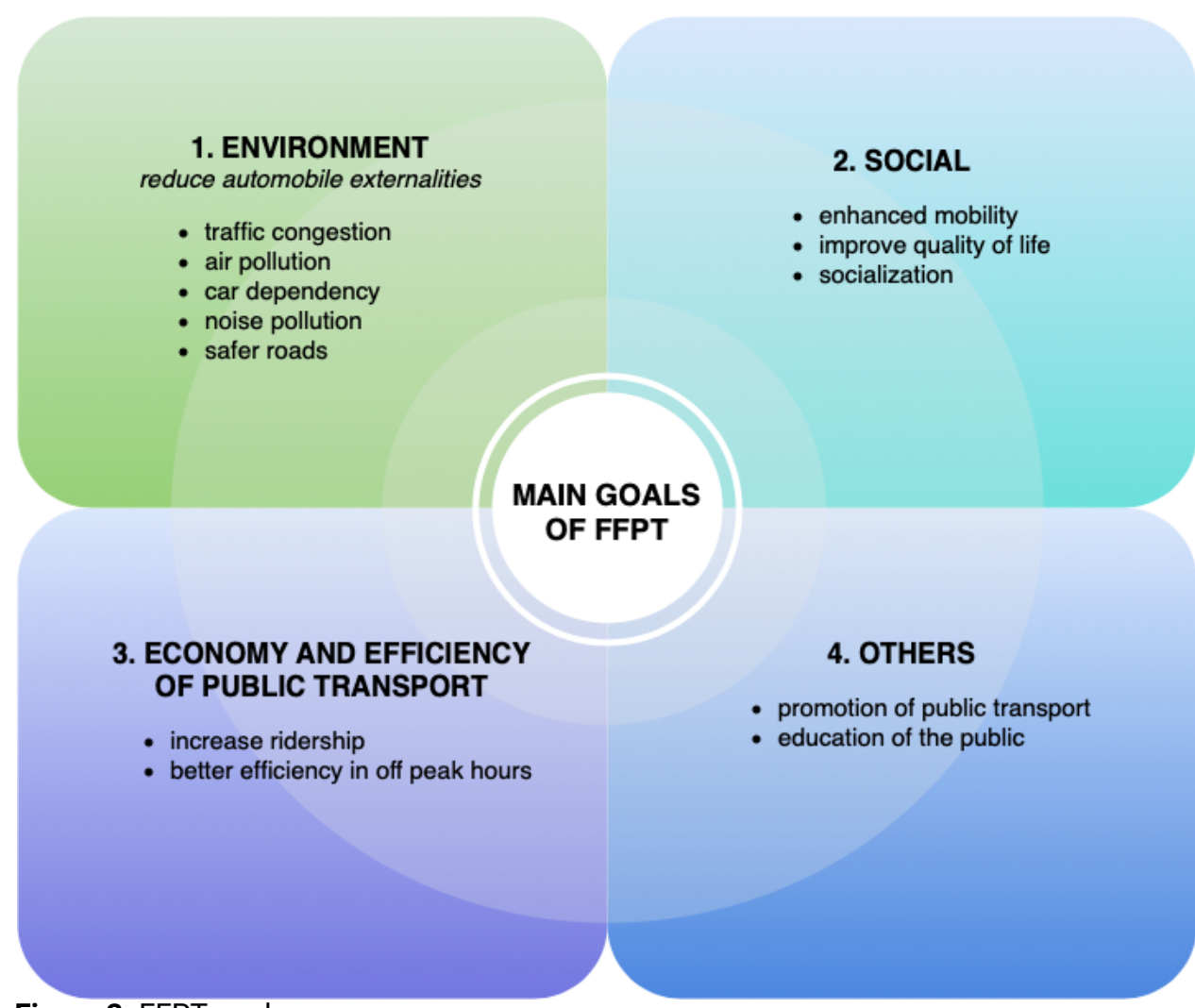

Figure 2. FFPT goals

Source: Author's compilation based on Fearnley, 2013; Hess, 2017; Keblowski, 2019.

First, the Environment set of goals represents the key reasons that initiated the creation of FFPT and they continue to be the main motivation for promoting this concept. Such a range of goals covers issues, which are closely tied to car-use externalities, for example, car accidents, traffic congestion, air and noise pollution, and the increasing dependency on cars. By abolishing fares, the municipalities are trying to encourage people, especially car drivers, to use public transport instead of cars (Storchmann, 2003; De Witte et al., 008; Zhou, Schweitzer, 2011; Cats et al., 2017).

Social goals are the second set of reasons to implement the system of FFPT. The main motivation is to increase mobility and to improve quality of life, not only for people with limited access to cars, which can result in less participation in everyday life but also for all the residents of the given city (Goeverden et al., 2006; Brand, 2008; Volinski, 2012; Fearnley, 2013; Chen, 2014; Cats a kol., 2017). The third group of goals is connected with economic dimensions and the efficiency of the public transport service. By making public transport free in offpeak hours there are some cities trying to support FFPT to boost the better overall efficiency of their service (Perone, 2002; D'Alessandro, 2008; Hess, 2017). The economic aspect can be improved by cutting costs connected with fares. This includes the production, collection, and the entire accounting system of tickets. 
Such savings, mainly in smaller cities or traffic systems, could provide sufficient resources for operating free fare transport (Goeverden et al., 2006).

The fourth group of goals, others, covers the promotion of public transport services and educating the public about sustainable mobility patterns of travel behaviour. This is usually done in the use of short-term periods like Car-Free Days, Mobility Week, etc. During such events, the public transport provider not only promotes its own service but also raises awareness about sustainable travel behaviour (Hodge et al., 1994; Perone, 2002).

In reality, each municipality highlights its particular reasons why implementing FFPT is useful for the city and traffic system. In the end, the system may also influence areas that were neglected in the initial planning stages, or may even generate new patterns of travel behaviour. In Templin (Germany), for example, the main goal for implementing FFPT was to reduce the use of cars. In addition to a slight decrease in traffic, the city noticed that there were fewer car accidents involving pedestrians and cyclists, generally regarded as the most dangerous means of transport. Safer roads mainly resulted from more pedestrians or cyclists choosing to use public transport (Strochman, 2003).

The goals mentioned above illustrate key elements or areas that municipalities are trying to improve with the use of FFPT. It is important to note that the implementation of FFPT always affects, to a certain extent, all aspects (environmental, social, etc., see Figure 2), not just the one that the city sees as the most problematic. The concept of free-fare transport policy does not stand alone in urban policy planning, as has already been mentioned, but is only one aspect of a whole range of tools urban policymakers can use to support and reach their visions. Therefore, it would be a huge mistake to see the concept of FFPT as a universal treatment for all transport-related issues. The evolution of transport systems is a very dynamic and complex process, and it is essential to have a systematic approach when overseeing it. Transport or urban strategies should be underpinned by a synergy of different tools and measures respecting the local context. The implementation of FFPT alone is not enough, and its use needs to be supported with other tools according to the primary goals.

\section{Examples of FFPT schemes in practice}

A good example is found in Hasselt (Belgium). The city transport system was suffering from many problems that can easily be found in almost every transport system around the world, namely, congestion, car accidents, increasing car use, air pollution, low mobility of seniors, and poor accessibility to the city centre stemming from ineffective public transport. Thanks to the city's systematic approach, however, it has had success dealing with these issues since the 1990s. The combination of a wide range of tools supports a more fruitful approach (Brand, 2008). By building a bypass road and decreasing the number of bus lines in the city centre, Hasselt reduced the number of cars in the city centre. In addition, closing parking areas in the centre and opening new ones around the 
outskirts of the city, which are linked to the public transport system and a network of cycle paths, also led to a decrease in the use of cars. Promotion and support of other means of transport, primarily the public transport network, is also key to Hasselt's success. A new fleet of buses, new connections and bus lines, and bus priority lanes together with the introduction of an FFPT scheme had a dramatic influence on bus patronage. In addition to a more efficient public transport and a decrease in car use, there was now better accessibility to the city centre, and the mobility of all inhabitants increased. By restricting cars access to the city centre through the promotion of non-motorised means of transport and by opening new cycling routes and creating more pedestrian zones, the city centre was also safer than before. Hasselt's transport strategy, of combining unique urban planning, technological innovation, and motivating citizens to travel by different means apart from automobiles, has created an area where each mode of transportation has its place and has improved the quality of both the local transport system and the quality of life for its residents.

Like the case of Hasselt, Nowy Tomysl (Poland), also wanted to solve issues connected with the increasing volume of cars and poor public transport connections between the city centre and the railway station (Janduła, 2016). The railway station is located $2 \mathrm{~km}$ from the city and commuters had to reach it by car. The municipality decided to introduce one bus line free of charge in order to improve the connection to the city and decrease car use. Despite the new connection, the badly planned timetable meant that the new bus line did not obtain the intended goal. Moreover, a new parking area was built, pointing towards future developments. Thus, Tomysl is a bad example of the use of FFPT. Instead of building a new parking area, the city should have focused on a more efficient public transport and more restrictions aimed at car use (an increase in the price of parking, for example).

Unsurprisingly, each municipality experiments with the concept of FFPT in different ways. Some scholars argue (Keblowski, 2018) that European cities typically use the concept as a tool to foster the sustainable development of traffic system, while North American cities use it to improve the efficiency of public transport (due to decreases in patronage). It is true that one finds more examples in North America than in Europe in which FFPT has been introduced to improve the overall quality of public transport, but that does not mean this has not occurred in Europe. In Europe, this improvement is found more frequently in smaller cities, which usually cover more than $50 \%$ of public transport operational costs, so the introduction of FFPT represents significant savings for the city budget. This is because the ticket revenues do not provide enough money to cover both operational costs and improvements in service. In cases where cities fund the public service by more than $50 \%$, the loss of ticket revenues together with the connected costs of tickets production, distribution, and accounting may free up additional financial resources. These sources can then be used later for improving the quality of the service. Of course, it is not the case for every city, but generally, small-sized cities with moderate public transport schemes are more likely to launch FFPT without profound changes to the budget. 
Although the introduction of FFPT means zero costs for the users, the loss of financial sources from ticket sales can cause difficulties in operating the service, namely when costs connected with tickets, such as their production, control units, accounting, etc., are eliminated (Volinsky, 2012; Perone, 2002). Significant financial savings are found in the case of small-scale cities and public transport schemes. In real practice, however, in most cases, the service provider must ensure coverage of the newly created deficit. By examining currently operating FFPT systems, one can easily find different solutions. One way is the so-called 'third-party payer system', in which the financial sources for public transport service are provided by a third party (Brown et al., 2001, 2003; De Witte et al., 2006; Volinsky, 2012). This is mainly the case of universities when they want to have free public transport on campus. A good example is the University of Virginia (Charlottesville, USA), where students pay a special annual fee to support the transport service. Individual cities are also looking for new ways to obtain additional financial sources for their budgets. In the city of Logan (Utah), the city council established a special transport-tax, which is used for public transport (Hodge et al., 1994). In cases where transport is only free for the residents of the city, the new deficit can be covered by tax revenues from these residents. This is what has happened in Tallinn (Estonia) where the city noticed that a growing numbers of people were registering in Tallinn in order to benefit from the free fare service.

\section{Case study: Frýdek-Místek}

The financing of free public transport in Frýdek-Místek (Czechia) works slightly differently. The FFPT system there is unique because the free public transport is not only available for the city's residents, but also for the surrounding villages. The current status is that the provider of public transport is also responsible for the bus connections to the surrounding area, which should be organized by a higher authority (Moravskolezský region). This means that public transport is being financed from three main sources - the city of Frýdek-Místek (73\%), Moravskoslezský region $(20 \%)$ and the included villages $(7 \%)$. The city is also trying to get some other financial revenue from its residents as one of the conditions for free public transport is that the residents cannot owe any debt to the city. Regardless, it must be said that according to the city authority, this amount is almost negligible.

Even though the city originally planned to only introduce the FFPT scheme within its administrative boundaries, in 2011 when the project was first launched, three other villages were already included. Nowadays the free public transport scheme includes 19 villages (in Table 2), but each resident decides individually whether to benefit from the free fare or not. In addition to riding free, the public transport pricing scheme allows riders to pay for single or monthly tickets. To benefit from free transport, one must have a special city card. 
Table 2. Characteristics of public transport in Frýdek-Místek

\begin{tabular}{lrrrrrrrr}
\hline & 2010 & 2011 & 2012 & 2013 & 2014 & 2015 & 2016 & 2017 \\
\hline PT costs (mil. CZK) & 33,989 & 67,075 & 62,680 & 68,982 & 62,450 & 68,981 & 68,378 & 78,182 \\
Sales (million CZK) & 24,826 & 19,891 & 14,781 & 15,056 & 16,659 & 15,511 & 15,401 & 13,236 \\
Fleet & 24 & 30 & 32 & 36 & 38 & 46 & 40 & 40 \\
Municipalities & 1 & 4 & 6 & 11 & 17 & 19 & 19 & 19 \\
Passengers (mil.) & 3,802 & 4,445 & 5,233 & 5,700 & 6,700 & 7,100 & 7,400 & 6,900 \\
\hline
\end{tabular}

Source: Frýdek-Místek 2016. Note: PT - public transport; CZK - Czech crown

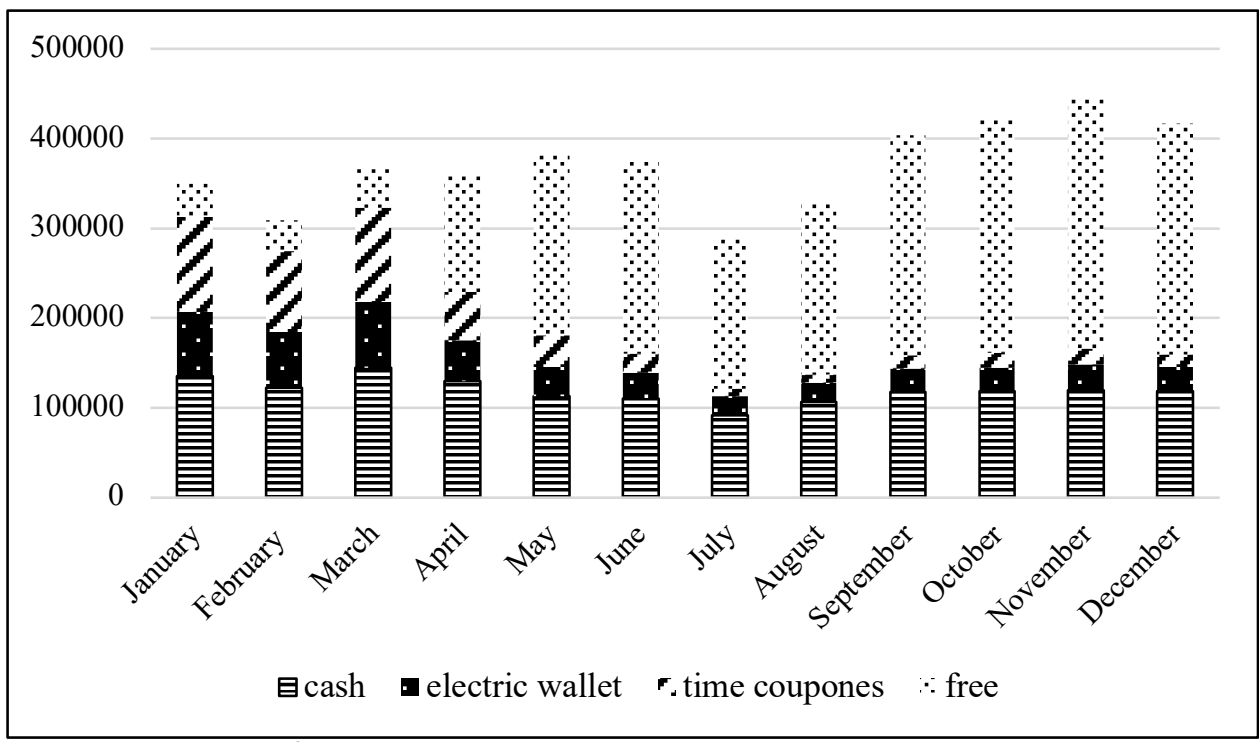

Figure 3. Structure of ridership in Frýdek-Místek, 2011

Source: Frýdek-Místek 2016

However, there has not been any dramatic rise in the budget deficit due to the abandonment of normal tariffs (see Table 2), as not all residents have immediately secured a card allowing them to use public transport for free. Naturally, operational costs have increased but this is not only due to the FFPT scheme but also because of major upgrades to the fleet and line extensions. In table 2 it is possible to see that as soon as FFPT was introduced, patronage began increasing, but only gradually.

Thanks to the free public transport policy, the city succeeded in increasing the ridership and efficiency of local public transport, which was one of the main goals of the project. The main reason, however, was to reduce the intensity of car traffic, which, due to the absence of a bypass to relieve transit traffic from the city centre, created a high burden for the city and was unsustainable for the future. The city was unable to provide us with sufficient evidence confirming whether or not they have met their goals, but according to the existing literature on free public transport, we may assume that to some extent it can motivate drivers to change their behaviour. Furthermore, free public transport is also attractive for pedestrians and cyclists, so it is not possible to state definitively if the increase in ridership is caused only by drivers and/or which group is more substantial. To 
have an overview of the possible effects of FFPT it is also important to look at other steps, which the city is taking to meet its stated goals. Unfortunately, in this case, it must be said that the city is lacking a systematic strategy. It is true that the city is attempting to support other means of transport (cycling) as well as restricting cars, but according to the city authority's opinion (Frýdek-Místek, 2016), we cannot expect that Frýdek-Místek will fulfil all the project's goals in the near future.

\section{Conclusion}

The concept of FFPT is part of a whole set of tools which are used to solve traffic and public transport-related problems. Different municipalities across the globe are using the concept for various reasons and many different goals. In general, the main goals are to improve the efficiency of the whole traffic system, the welfare of its citizens and their living conditions and overall to push urban development closer to a sustainable trajectory. Free fare transport policy is being used to support solutions for environmental, social, and traffic-related challenges. Each city's transport system is unique as is its development, which is influenced by particular issues such as historical development, the travel behaviour of the residents, and other measures influencing traffic and urban development. The same is true for the concept of FFPT, which is not a universal model to heal every issue concerning traffic problems due to the high rate of car use or insufficient accessibility to public transport. Implementation of the FFPT system should respect current urban conceptual documents, and other measures should support it. The system itself, as has been mentioned many times, is not self-supporting, but it is part of a wide range of measures or tools with supportive or restrictive impacts on transport systems. As suggested by the evidence from cities which have implemented FFPT schemes, a multifaceted approach is essential to reach the main goals. It is also important to note that the system is not suitable for every city. It turns out that the size of the city plays an important role because the system is mainly used in small to medium-size cities (in the case of unlimited FFPT systems), as introducing it there is easier. Bigger cities tend to launch only partial implementations of FFPT, usually integrating it with park \& ride systems.

The Frydek-Místek study shows that in cases when the FFPT scheme is wellestablished, it does not lead to significant drops in ticket revenues, nor does it place any burden on city budgets. Thanks to a multilateral agreement and cooperation between local/regional stakeholders, which benefit from free fare transport, together with the sale of standard tickets, the city has been able to finance the whole project sustainably. In this example, the surrounding (suburban) municipalities and the regional government, which are obliged to provide their citizens with transport services, are involved in financing the project. In addition, commercial partners providing business or cultural services that can make significant profits by improving accessibility for citizens can be also involved. This confirms that if the system is well-designed and respects the local 
context, its implementation might be highly effective. Nevertheless, it is still necessary to focus on the ability of the concept to motivate drivers to change their transport behaviour and reduce the use of cars. Effective use of the system requires that it remains stable over time. All city councils across the political spectrum should accept the implementation of FFPT, which is essential if the system will continue to work for more than one term of office.

\section{Acknowledgments}

This article was written with the support of the project GAUK 54515: Transport related social exclusion in microregions of Czechia (2015-2017).

\section{References}

Banister, D. (2000), "Sustainable urban development and transport - a Eurovision for 2020", Transport Reviews, vol. 20, no. 1, p. 113-130.

Banister, D. and Marshall, S. (2000), Encouraging transport alternatives, Stationery Office, London.

Banister, D. and Hickman, R. (2006), "How to design a more sustainable and fairer built environment: transport and communications", IEEE Proceedings Intelligent Transport Systems, vol. 153, no. 4, p. 276-291.

Banister, D. (2008), "The sustainable mobility paradigm", Transport Policy, vol. 15, no. 2, p. 73-80.

Baum, H.J. (1973), "Free Public Transport", Journal of Transport Economics and Policy, vol. 7, no. 1, p. 3-19.

Bly, P. and Oldfield, R. (1986), "The effects of public transport subsidies on demand and supply", Transportation Research Part A, vol. 20, no. 6, p. 415-427.

Brand, R. (2008), "Co-Evolution of Technical and Social Change in Action: Hasselt's Approach to Urban Mobility", Built Environment, vol. 34, no. 2, p. 189199.

Brown, J., Hess, D.B. and Shoup, D. (2003), "Free-Fare Public Transit at Universities", Journal of Planning Education and Research, vol. 23, no. 1, p. 69-82.

Brown, J., Hess, D.B. and Shoup, D. (2001), "Unlimited Access", Transportation, vol. 28, no. 3, p. 233-267.

Cats, O., Susilo, Y. and Reimal, T. (2017), "The prospects of free-fare public transport: evidence from Tallinn", Transportation, vol. 44, no. 5, p. 1083-1104.

Cervero, R. (1990), "Transit pricing research - a review and synthesis", Transportation, vol. 17, no. 2, p. 117-139.

Chen, C., Varley, D. and Chen, J. (2011), "What affects Transit Ridership? A Dynamic Analysis involving Multiple Factors, Lags and Assymetric Behaviour", Urban Studies, vol. 48, no. 9, p. 1893-1908. 
Chen, X. (2014), How do free public transport policy affects the travel behaviour of individual, School of Architecture and the Built Environment KTH Royal Institute of Technology, Stockholm.

Church, A., Frost, M. and Sullivan, K. (2000), "Transport and social exclusion in London", Journal of Transport Policy, vol. 7, no. 3, p. 195-205.

D'Alessandro, A. (2008), "Free-Fare Transit - A Strategy for Sustainable Transportation", Urban Transit: What is Really Need for Sustainable Future Session, 2008 Annual Conference Association of Canada, Urban Transit, Toronto.

De Witte, A., Macharis, C., Lannoy, P., Polain, C., Steenberghen, T. and Van De Walle S. (2006), "The impact of 'free' public transport: The case of Brussels", Transportation Research Part A, vol. 40, no. 8, p. 671-689.

De Witte, A., Macharis, C. and Mairesse, O. (2008) "How persuasive is 'free' public transport? A survey among commuters in the Brussels Capital Region", Transport Policy, vol. 15, no. 4, p. 216-224.

Fearnley, N. (2013), "Free Fares Policies: Impact on Public Transport Mode Share and Other Transport Policy Goals", International Journal of Transportation, vol. 1, no. 1, p. 75-90.

Frýdek-Místek (2016), Base dataset and information about the project 'MHD Zdarma' (FFPT), DaSH.

Goeverden, C., Rietvield, P., Koelemejer, J. and Peeters, P. (2006), "Subsidies in Public Transport", European Transport, vol. 6, no. 32, p. 5-25.

Green, L.D. and Wegner, M. (1997), "Sustainable transport", Journal of Transport Geography, vol. 5, no. 3, p. 177-190.

Haire, A.R. and Machemehl, R.B. (2007), "Impact of rising fuel prices on U.S. transit ridership", Transportation Research Record: Journal of the Transportation Research Board, vol. 1992, no. 1, p. 11-19.

Hess, D.B., (2017), "Decrepting fare-free public transport in Tallinn, Estonia", Case Studies on Transport Policy, vol. 5, no. 4, p. 690-698.

Hine, J. (2008), "Transport and social justice" in R.D Knowles, J. Shaw and I. Docherty (eds) Transport Geographies Mobilities, Flows and Spaces, JohnWiley/Blackwells, Oxford.

Hodge, D., Orell J.D. and Strauss T.R. (1994), Free-fare policy: costs, impacts on transit service, and attainment of transit system goals, Washington State Transportation Centre, Washington D.C..

Janduła, M. (2016), "Nowy Tomyśl nie widzi efektów darmowj komunikacji (Nowy Tomyśl can not see the eefect of free transport)", Transport Publiczny, viewed 12 November 2018, https://urlzs.com/CCncn.

Jaroš, V. (2017), "Social and transport exclusion", Geographia Polonica, vol. 90, no. 3, p. 247-263.

Keblowski, W. (2018), "Free Public Transport: scope and definitions" in J. Dellheim and J. Pince (eds.), Free Public Transit: And Why Don't We Pay To Ride Elevators, Black Rose Books, Montreal, p. 1-7.

Keblowski, W. (2019), "Why (not) abolished fares? Exploring the global geography of free-fare public transport", Transportation, p. 1-29. 
Kenyon, S. (2011), "Transport and social exclusion: access to higher education in the UK policy context", Journal of Transport Geography, vol. 19, no. 4, p. 763-771. Kenyon, S., Lyons, G. and Rafferty, J. (2002), "Transport and Social Exclusion: Investigating the Possibility of promoting Inclusion through Virtual Mobility", Journal of Transport Geography, vol. 10, no. 3, p. 207-209.

Litman, T. (2004), "Transit Price Elasticities and Cross-Elasticities", Journal of Public Transportation, vol. 7, no. 2, p. 37-58.

Lucas, K. (2012), "Transport and social exclusion: Where we are now", Transport Policy, vol. 20, p. 105-113.

Perone, J.S. (2002), Advantages and Disadvantages of Free Fare Transit Policy, Center for Urban Transportation Research, Tampa.

Pojani, D. and Stead, D. (2015), "Sustainable Urban Transport in the Developing World: Beyond Megacities", Sustainability, vol. 7, no. 6, p. 7784-7805.

Preston, J. and Rajé, F. (2007), "Accessibility, mobility and transport-related social exclusion", Journal of Transport Geography, vol. 15, no. 3, p. 151-160.

Redman, L., Friman, M., Garling, T. and Harting, T. (2013), "Quality atributes of public transport that attract car users: A research review", Transport Policy, vol. 25, p. 119-127.

Sheller, M. and Urry, J. (2006), "The new mobilities paradigm", Environment and Planning A, vol. 38, no. 2, p. 207-226.

Scheiner, J.I. and Starling, G. (1974), "The Political Economy of Free-Fare Transit", Urban Affairs Review, vol. 10, no. 2, p. 170-184.

Storchmann, K. (2003), "Externalities by Automobiles and Free-Fare Transit - A Paradigm Shift?", Journal of Transport Geography, vol. 6, no. 4, p. 59-69.

Tao, S. (2013), "The Measerues \& Experience of Implementing Free Public Transport in Chengdu", Tallinn: Capital of Free Public Transport, Tallinn City Government, Tallinn, p. 9, viewed 27 June 2018, https://urlzs.com/r5hGC.

Tetřevová, L. (2008), Veřejná ekonomie, Příbram, Proffesional publishing.

Van Goeverden, C., Rietvield, P., Koelemeijer, J. and Peeters, P. (2006), "Subsidies in public transport", European Transport, vol. 6, no. 32, p. 5-25.

Volinski, J. (2012), Implementation and Outcomes of Free-Fare Transit System: a Synthesis of Transit Price, Transportation Research Board, Washington.

Zhou, J.H. and Schweitzer, L. (2011), "Getting Drivers to Switch: Transit Price and Service Quality among Commuters", Journal of Urban Planning, vol. 137, no. 4, p. 477-483. 